\title{
Understanding Subdural Collections in Pediatric Abusive Head Trauma
}

\author{
(DD. Wittschieber, (DB. Karger, DH. Pfeiffer, and (DM.L. Hahnemann
}

\begin{abstract}
SUMMARY: Life-threatening physical abuse of infants and toddlers is frequently correlated with head injuries. A common variant of the abusive head trauma is the shaken baby syndrome. The present review article sheds light on subdural collections in children with abusive head trauma and aims at providing a recent knowledge base for various medical disciplines involved in diagnostic procedures and legal proceedings. To this end, the different subdural collection entities are presented and illustrated. The pathophysiologic background is explained. Differential and age-diagnostic aspects are discussed and summarized by tabular and graphic overviews. Two problematic constellations frequently occurring during initial CT investigations are evaluated: A mixed-density subdural collection does not prove repeated trauma, and hypodense subdural collections are not synonymous with chronicity. The neuroradiologic analysis and assessment of subdural collections may decisively contribute to answering differential diagnostic and forensic questions. In addition to more reference data, a harmonization of terminology and methodology is urgently needed, especially with respect to age-diagnostic aspects.
\end{abstract}

ABBREVIATIONS: $\mathrm{AHT}=$ abusive head trauma; $\mathrm{BV}=$ bridging vein; $\mathrm{CSDH}=$ chronic subdural hematoma; SDC = subdural collection; SDE = subdural effusion; $\mathrm{SDH}=$ subdural hematoma; SDEm = subdural empyema; SDHy = subdural hygroma; SDHHy = subdural hematohygroma

n light of serious physical, psychological, and legal consequences, physical child abuse attracts increasing attention in terms of health policy and health economy. ${ }^{1-3}$ Head injuries represent the most frequent cause of lethal outcome and mainly relate to children within their first and second years of life. ${ }^{4-6}$ Currently, the term "abusive head trauma" (AHT) is used for any nonaccidental or inflicted head injuries in pediatrics. ${ }^{7-9}$

AHT has a worldwide incidence of 14-30/100,000 live births among children younger than 1 year of age. ${ }^{5,10-13}$ Additionally, a high amount of underreporting has to be assumed because many cases are not identified due to subclinical courses, nonspecific symptoms, or missing medical consultation. ${ }^{14}$ Meta-analyses on the outcome revealed an average mortality rate of around $20 \%$ among children younger than 2 years of age. ${ }^{15}$ Survivors showed severe disability (eg, tetraplegia, epilepsy, or blindness) in $\sim 34 \%$,

Received June 18, 2018; accepted August 16

From the Institute of Legal Medicine (D.W., B.K., H.P.), University Hospital Münster, Münster, Germany; Institute of Legal Medicine (D.W.), Friedrich Schiller University Jena, Jena, Germany; Institute of Diagnostic and Interventional Radiology and Neuroradiology (M.L.H.), University Hospital Essen, Essen, Germany; and Department of Neuroradiological Diagnostics and Intervention (M.L.H.), Medical Centre HamburgEppendorf, Hamburg, Germany.

Please address correspondence to Daniel Wittschieber, MD, PhD, Institute of Legal Medicine, Friedrich Schiller University Jena, Am Klinikum 1, 07747 Jena, Germany; e-mail: daniel.wittschieber@med.uni-jena.de

- Indicates open access to non-subscribers at www.ajnr.org

http://dx.doi.org/10.3174/ajnr.A5855 and moderate disability (eg, hemiplegia, memory and attention difficulties) in $\sim 25 \%$ of the cases. ${ }^{15}$

The shaken baby syndrome-a common variant of AHT with increasing general public awareness-is characterized by the following features that are neither obligatory nor evidentiary:

- Acute encephalopathy, being the clinical expression of traumatic damage of the brain parenchyma accompanied by a wide spectrum of neurologic symptoms that depend on the intensity of the trauma.

- Subdural collections with or without additional extra-axial findings such as subarachnoid hemorrhage, arachnoid tear, or bridging vein thrombosis.

- Retinal hemorrhages typically found in many locations, within several layers, disseminated, widespread from the center to the periphery, and with or without additional retinoschisis or intravitreal hemorrhage.

- Spinal trauma such as ligamentous injuries at the craniocervical junction, or spinal sub- or epidural hematomas.

- No or only minimal injuries of the skin because skin bruises caused by firm grip at the arms or the thorax of the child are rare.

- Missing or inadequate anamnesis — that is, no trauma reported or report of just a minor trauma despite the presence of severe brain injury.

With respect to other variants of AHT, further features of head injury may occur, in particular, signs of blunt force (impact) 
trauma against the child's head such as skin lesions or skull fractures.

Relevant differential diagnoses such as metabolic disorders, infectious and hematologic diseases, and birth trauma must be excluded. However, these differential diagnoses usually cannot explain the symptomatology of AHT as a whole. Diagnosing AHT always requires the joint assessment of numerous investigation results from pediatrics, ophthalmology, neurosurgery, laboratory medicine, forensic medicine, and radiology. ${ }^{7,16}$ Pediatric neuroimaging by CT and MR imaging plays a key role in this strategy. ${ }^{7,16,17}$ Traumatic brain injuries and extra-axial indicators of AHT can be depicted and evaluated across time. Besides subarachnoid hemorrhages, fluid collections within the subdural space represent such extra-axial indicators of AHT.

\section{SUBDURAL COLLECTIONS}

The term "subdural collection" (SDC) is understood as a nonspecific umbrella term comprising various, in part, successively stagelike findings within the subdural space. The radiologic investigation of SDCs has the potential to contribute to important issues such as type, number, and circumstances of the traumatic force or the age of injury. Apart from the clinical and medicolegal significance for the diagnosis of child abuse, SDCs may also be relevant for criminological aspects because age estimation possibly facilitates further limitation of the circle of suspects.

Differential diagnostics of the various SDC entities is a challenging topic for the radiologist. During the initial image-assessment process, the more careful labeling as SDC may be more reasonable than the possibly hasty determination of a special SDC entity. ${ }^{18,19}$ Terminology and definition criteria of the SDC entities are inconsistent, even among experts. This issue may partly be attributed to the frequent presence of mixed or transitional SDC forms. However, the large body of literature allows the differentiation of at least the following 6 entities.

\section{Subdural Hematoma}

In the context of AHT, subdural hematoma (SDH) is described as the most common intracranial pathology in infants and toddlers. ${ }^{20-22}$ SDHs, like all SDCs, may occur unilaterally or bilaterally. ${ }^{23}$ The convexities of the cerebral hemispheres (Fig 1A), the falx cerebri, the tentorium cerebelli, and the middle and posterior cranial fossae are considered typical locations. ${ }^{22}$ In many cases, SDHs have a key role as a diagnostic marker only - that is, though they may represent an important symptom of child abuse, their volumes are often small, resulting in just a minor space-occupying effect..$^{8,21,23-25}$ Hence, frequently, SDHs do not have a prognostic relevance for the extent of brain damage. ${ }^{24}$ Depending on the developmental stage in which subdural blood is visualized by neuroimaging, SDHs have a wide variety of appearances (Table 1). The chronic SDH has a special position (see below: "Chronic Subdural Hematoma”).

\section{Subdural Hygroma}

The term subdural hygroma (SDHy) is classically reserved for proteinaceous, clear, pink-tinged, or xanthochromatic collections within the subdural space containing pure CSF or at least CSF-like fluid; blood, blood products, or neomembranes are nonexistent by definition (Fig $1 B,-C){ }^{22,26,27}$ However, the smallest amounts of blood within the SDHy cannot always be excluded and may become noticeable on CT by a slightly higher density compared with CSF (see below: "Subdural Hematohygroma," "homogeneous variant").

\section{Subdural Hematohygroma}

Subdural hematohygromas (SDHHys) are a combination of blood (or blood products) and CSF (or CSF-like fluid). ${ }^{22,28-30} \mathrm{~A}$ homogeneous and a heterogeneous variant can be differentiated.

In many cases of an SDC diagnosed as SDHy, it may be assumed that the SDC is actually the homogeneous variant of the SDHHy (Fig 1D) because the blood component may sometimes be relatively small and/or very "young" (hyperacute); furthermore, an intense mixture of blood and CSF may be present. ${ }^{27-29}$ Hence, in our experience, SDHy and SDHHy are used interchangeably or synonymously in radiology reports.

The heterogeneous variant of the SDHHy (Fig $1 E,-F$ ) indicates 2 SDC components that coexist within the same subdural compartment (eg, above a brain convexity); these components may be clearly distinguished from one another (fluid-fluid levels possible) and may appear hyper- and hypodense during CT investigations (mixed-density pattern)..$^{22,28,30-32}$ The hypodense component is interpretable as the following:

1) Acute CSF collection (eg, due to an arachnoid tear, see below: "Pathophysiology")

2) Supernatant (and thus an integral part of blood) changed by gravity (serum separation/blood sedimentation/hematocrit effect), in the sense of an SDH.

Of course, a mixed form of both variants is conceivable as well (ie, simultaneous presence of CSF influx and blood sedimentation; see below: "Mixed-Density SDCs: Repeated Trauma?" and Table 2, upper part).

\section{Chronic Subdural Hematoma}

Currently, from the pathophysiologic point of view, chronic subdural hematoma ( $\mathrm{cSDH})$ is considered a separate SDC entity. ${ }^{23} \mathrm{cSDH}$ denotes a serosanguinous, petroleum-, or crankcase-like fluid collection surrounded and sometimes loculated (divided into compartments) by neomembranes (Fig 1G, $-I) .{ }^{26,33-35}$ Neomembranes contain numerous new blood vessels leading to accumulation of contrast agent in neuroimaging studies. $^{22,27}$ The presence of neomembranes represents an important criterion for distinguishing $\mathrm{cSDH}$ and SDHy. In contrast to the situation in adults, genuine cSDHs are relatively rare in infants. ${ }^{22,36-38}$

\section{Subdural Effusion and Subdural Empyema}

These proteinaceous SDC entities are predominantly considered sequelae (in case of subdural effusion [SDE]) or complications (in case of subdural empyema [SDEm], eg, due to an infected SDE) of bacterial meningitis or sinusitis. ${ }^{22,39}$ These conditions usually do not cause diagnostic difficulties because inflammatory symptomatology or a history of CNS infection is typically present. Normally, SDEs and SDEms are nontraumatic, but in rare cases, SDEms may originate following penetrating head trauma or craniotomy, which, of course, is usually known in the clinical setting. 

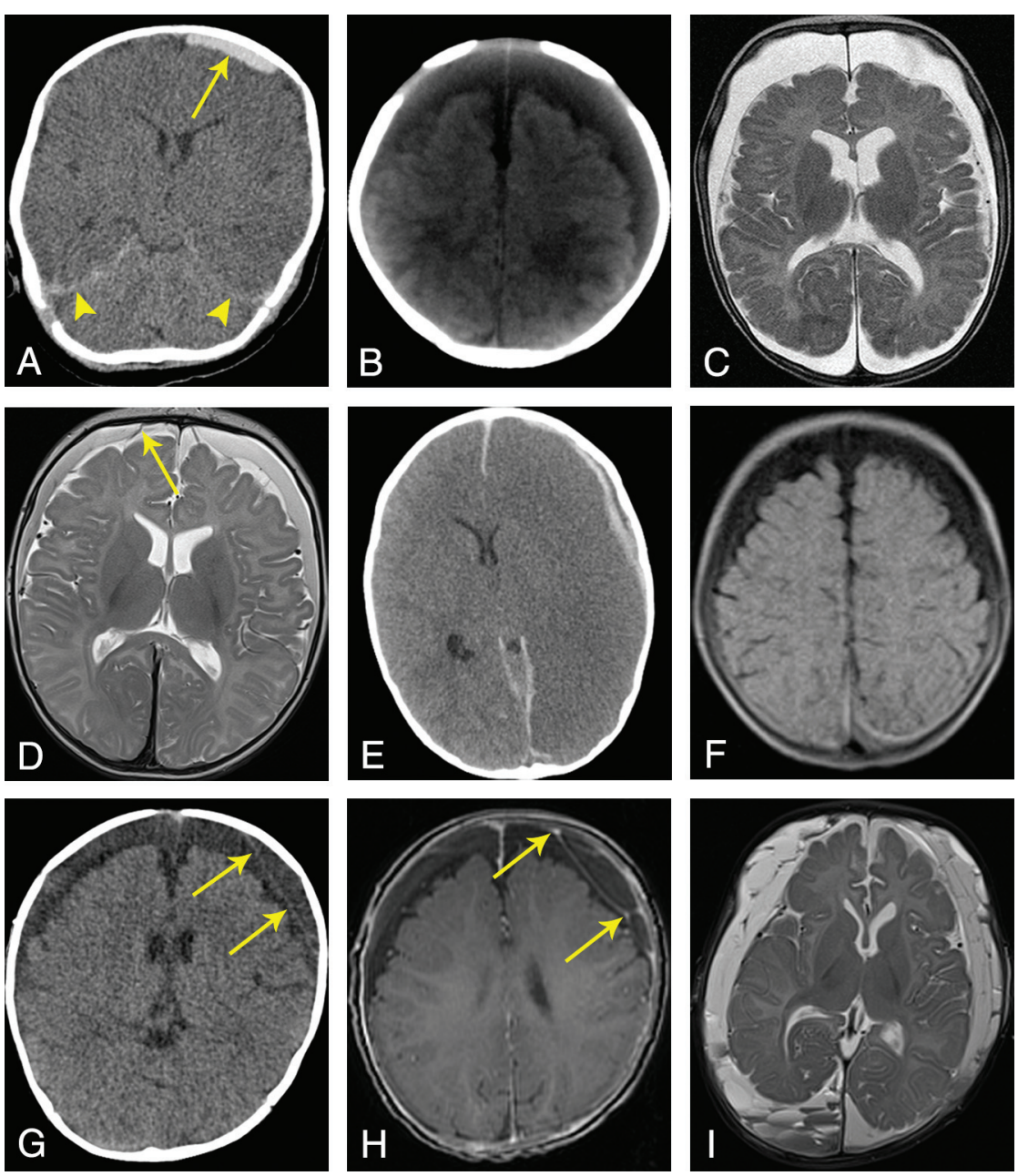

FIG 1. SDC entities in AHT cases. A, Acute SDH (nonenhanced CT): a 2-month-old boy with a small hyperdense SDC over the left frontoparietal region (arrow) and hyperdense blood components around the tentorium (arrowheads). B, SDHy (nonenhanced CT): a 2-month-old boy with wide, homogeneously hypodense (or CSF-isodense) SDCs over both frontoparietal regions; no neomembranes or septa. C, SDHy (MR imaging, T2WI, TSE, nonenhanced): a 4-month-old boy with wide, homogeneously CSF-isointense SDCs over both frontoparietooccipital regions, markedly frontal due to the supine position; no neomembranes or septa. D, SDHHy, homogeneous variant (MR imaging, T2WI, TSE, nonenhanced): a 3-month-old boy with homogeneous SDCs over both frontoparietal regions. Compared with CSF within the external and internal CSF spaces, the SDCs appear hypointense. Two intact BVs can be found next to the superior sagittal sinus (arrow shows $1 \mathrm{BV}$ ). E, SDHHy, heterogeneous variant (nonenhanced CT): a 19-month-old boy with an SDC in the left frontoparietal region. The SDC is composed of a thin, brain-sided, hyperdense component and a thin, dura-sided, hypodense component that runs parallel to the former component (mixed-density pattern). In this case, the study also revealed severe brain edema with a midline shift to the right side as well as hyperdense blood components within the anterior and posterior interhemispheric fissures. $\mathrm{F}, \mathrm{SDHHy}$, heterogeneous variant (MR imaging, FLAIR, nonenhanced): a 4-month-old girl with wide SDCs over both frontoparietooccipital regions. While the frontoparietal SDC proportions appear hypointense, the parietooccipital proportions are iso- to hyperintense. The transitional zone between the 2 components is almost smooth; fluid-fluid levels cannot be recognized unambiguously. G, Chronic SDH (nonenhanced CT): a 7-monthold boy with wide, hypodense SDCs over both frontoparietal regions and subtle formation of subdural neomembranes on the left side (arrows). H, Chronic SDH (MR imaging, TTWI, gradient-echo sequence, enhanced by contrast agent): same case as in $G$. Confirmation of the presence of subdurally located septa and chamber formations. In contrast to the nonenhanced TTWI (not shown), this contrast agent-enhanced study revealed focal signal enrichment located at the neomembranes (arrows). I, Chronic SDH (MR imaging, T2WI, TSE, nonenhanced): a 4-month-old boy with numerous subdural septa and neomembranes. Note the different signal intensities and multiple fluid-fluid levels within subdural chamber formations, especially in the right occipital region.

\section{PATHOPHYSIOLOGY}

AHT is predominantly caused by acceleration-deceleration trauma, blunt force trauma (impact), or a combination of these mechanisms. ${ }^{8,9,40}$ In acceleration-deceleration trauma, the child is usually held firmly at the thorax or upper arms and is then shaken. These rapid movements result in repeated acceleration and deceleration of the child's head due to missing postural control. Shearing and rotational forces may cause severe injuries within the brain tissue, determining prognosis. In addition, small and medium-sized blood vessels within the cranial cavity, particularly the bridging veins (BVs) that mainly run through the subarachnoid space, may rupture in part or completely. Approximately 50 BVs (diameter, 0.05-3.07 mm) connect the cortical veins of the cerebral and cerebellar surface with the large venous sinuses, thereby penetrating the inner part of the dura mater. ${ }^{41}$ Typically, injuries of the BVs cause extra-axial hemorrhage, predominantly within the subarachnoid and subdural spaces. ${ }^{23,41-44}$

BVs show a different wall thickness at different locations. While the BV wall measures 50-200 $\mu \mathrm{m}$ within the subarachnoid space, the BV segments that penetrate the dura mater may have a wall thickness of only $10 \mu \mathrm{m}$ and do not show additional external strengthening by connective tissue. ${ }^{45}$ Thus, increased vulnerability of dural BV portions is assumed. ${ }^{45}$ The resulting hemorrhage from the injured BVs fosters opening of the subdural space. This pathologic space does not exist under physiologic conditions and has been recognized as an intradural lesion caused by cleavage of the innermost part of the dura mater, the dura border cell layer. ${ }^{22,46,47}$ Nevertheless, the traditional term "subdural" is still widely in use; thus, BV hemorrhage leads to what is generally referred to as SDH.

Due to shearing forces, the arachnoid membrane may also tear (eg, in the vicinity of strained BVs or at Pacchionian granulations). ${ }^{29,48}$ If this is the case, transfer of CSF from the subarachnoid space to the subdural space is possible. Thus, an SDHy or SDHHy may develop additionally or subsequently (yellow box in Fig 2).27,29,49 The laceration of the arachnoid membrane may function as a valve preventing backflow of CSF. ${ }^{49,50}$ Besides this rapid mechanism, occurring within a few minutes or hours, delayed formations of SDHys and SDHHys, requiring up to several days, have been observed as well. ${ }^{27}$ Etiopathologically, there are 2 causative mechanisms: 
Table 1: Classic SDH stages in CT and MRI (at 1.5T)

\begin{tabular}{|c|c|c|c|c|c|}
\hline \multirow[b]{2}{*}{ Characteristics } & \multicolumn{5}{|c|}{ Stage } \\
\hline & Hyperacute & Acute & Early Subacute & Late Subacute & Chronic \\
\hline Assumed time range ${ }^{b}$ & Min: 0 hr & Min: 1 day & Min: 2 days & Min: 1 wk & Min: 2 wk \\
\hline & Max: $24 \mathrm{hr}$ & Max: 3 days & Max: 2 wk & Max: 3 wk & \\
\hline NECT ${ }^{c}$ & $\downarrow / \leftrightarrow$ & $\uparrow$ & $\uparrow$ & $\leftrightarrow$ & $\downarrow$ \\
\hline $\mathrm{MRI}^{\mathrm{C}}(\mathrm{TI})$ & $\leftrightarrow$ & $\leftrightarrow$ & $\uparrow$ & $\uparrow$ & $\downarrow$ \\
\hline$M R I^{c}(T 2)$ & $\uparrow$ & $\downarrow$ & $\leftrightarrow / \uparrow$ & $\uparrow$ & $\uparrow$ \\
\hline Hb state & $\mathrm{Oxy}-\mathrm{Hb}$ & Desoxy-Hb & Met-Hb & Met-Hb & Ferritin/hemosiderin \\
\hline Hb localization & Intracellular & Intracellular & Intracellular & Extracellular & Extracellular \\
\hline Fe oxidation state & $\mathrm{Fe}^{2+}$ & $\mathrm{Fe}^{2+}$ & $\mathrm{Fe}^{3+}$ & $\mathrm{Fe}^{3+}$ & $\mathrm{Fe}^{3+}$ \\
\hline Pathophysiology & $\begin{array}{l}\text { Unclotted } \\
\text { blood }\end{array}$ & $\begin{array}{l}\text { Clotted blood, } \\
\text { clot retraction }\end{array}$ & $\begin{array}{l}\text { Max clot retraction, } \\
\text { erythrocytes predominantly } \\
\text { (still) intact, oxidative } \\
\text { denaturation of the } \\
\text { desoxy-Hb into met-Hb }\end{array}$ & $\begin{array}{l}\text { Lysis of erythrocytes, thereby } \\
\text { increase of extracellular met-Hb, } \\
\text { start of disintegration to heme } \\
\text { and globin, Fe } \mathrm{Fe}^{3+} \text { is stored } \\
\text { within the macromolecule ferritin } \\
\text { and the phagocytic product } \\
\text { hemosiderin, respectively }\end{array}$ & $\begin{array}{l}\text { In contrast to intraparenchymal } \\
\text { hematomas, removal of ferritin } \\
\text { and hemosiderin within the } \\
\text { extra-axial space is accelerated } \\
\text { due to the missing blood-brain } \\
\text { barrier (therefore } \uparrow \text { in T2) }\end{array}$ \\
\hline
\end{tabular}

Note:-NECT indicates nonenhanced CT; Hb, hemoglobin; $\uparrow$, hyperdense/hyperintense; $\downarrow$, hypodense/hypointense; $\leftrightarrow$, isodense/isointense; Min, minimum; Max, maximum; Desoxy-Hb, Desoxy-Hemoglobin; Oxy-Hb, Oxy-Hemoglobin; Met-Hb, Met-Hemoglobin.

${ }^{a}$ According to Hedlund, ${ }^{22}$ Vezina, ${ }^{28}$ Lee et al, ${ }^{61}$ Duhem et al, ${ }^{62}$ Tung, ${ }^{63}$ Cramer et al, ${ }^{64}$ Bradley, ${ }^{65}$ and Bergström et al. ${ }^{66}$

b Due to insufficient data base, the time intervals stated do not represent absolute borders- that is, the ranges may be exceeded or undercut in single cases.

${ }^{c}$ Density/signal intensity compared with cortical brain tissue.

Table 2: Mixed-density and hypodense SDCs - 2 typical problem constellations during the initial CT investigation ${ }^{a}$

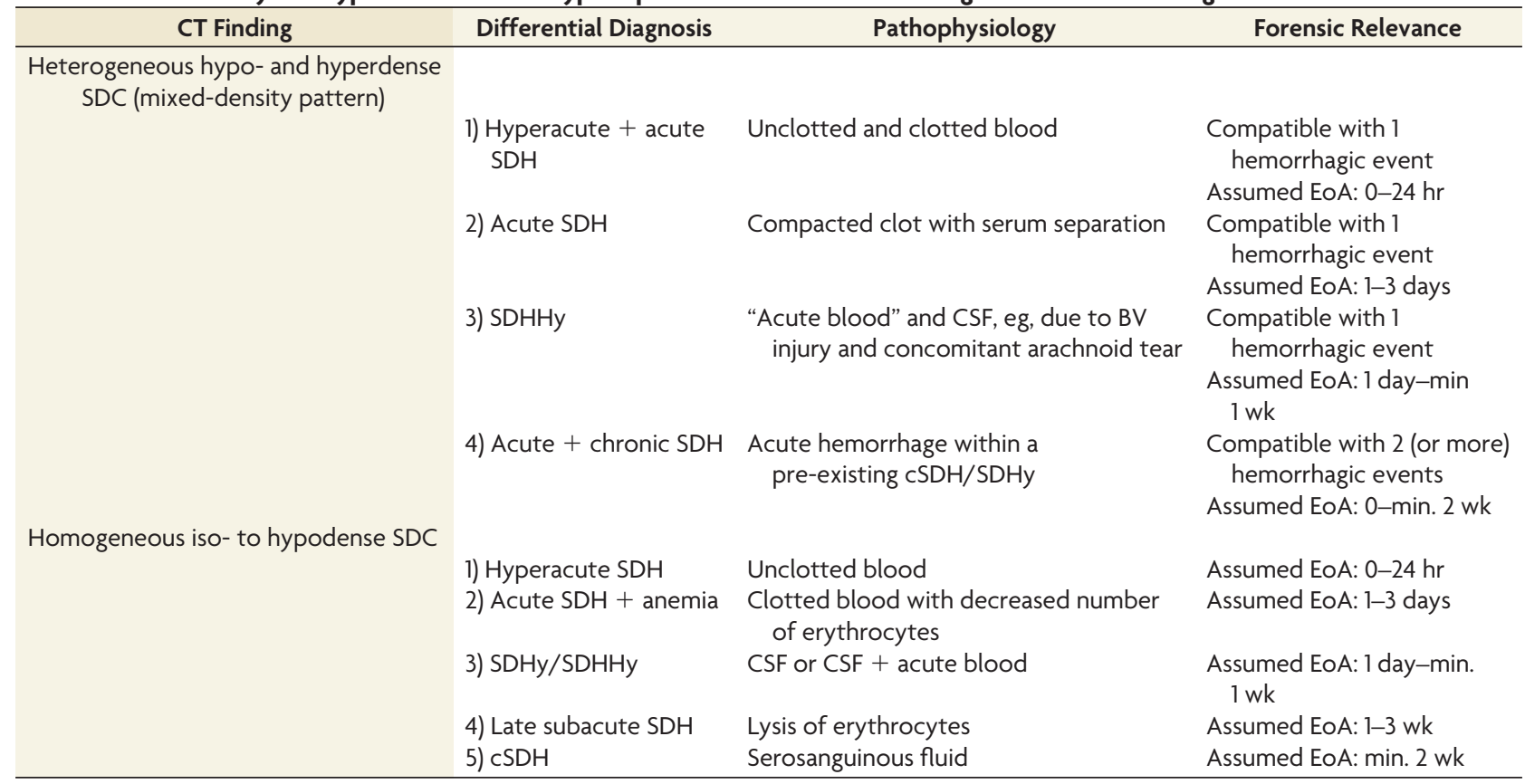

Note:-EoA indicates estimate of age; min, minimum.

${ }^{a}$ According to Hymel et al, ${ }^{20}$ Hedlund, ${ }^{22}$ Vezina, ${ }^{28}$ and Tung et al. ${ }^{30}$

1) Influx of CSF or CSF-like fluid as a result of a posttraumatic, reactive, vasomotoric (diffusion) disorder within surrounding meningeal structures. This is assumed to occur particularly with decreased intracranial pressure and through the mediation of cytokines. $^{20,22,33,34,51,52}$

2) Pathologic accumulation of intradural CSF that is assumed to move physiologically within the dural venous plexus from the subarachnoid space to the venous sinuses. ${ }^{47}$

Likewise, the further development toward $\mathrm{cSDH}$ is not yet completely understood. However, it seems clear that an outer subdural neomembrane (at the dural side) is primarily formed. Its formation commences at the innermost cell layer of the dura mater cleaved by the SDC. Subsequently, an inner subdural neomembrane (on the arachnoid side) is formed so that, finally, both neomembranes surround the SDC. ${ }^{53-56}$ Particularly the thicker outer neomembrane is highly vascularized. Leakage of these fragile new blood vessels is held responsible for additional influx of blood, proteins, and fluid and, thereby, for the increase in size of the $\mathrm{cSDH} .{ }^{39,52-56}$ Formation of septa is considered a consequence of repeated rebleeding events and may lead to chamber-like structures with multiple fluid-fluid levels appearing differently with regard to density or signal intensity (Fig $1 I$ ). ${ }^{57} \mathrm{~A}$ pathologically expanding SDHy or SDHHy is considered the precursor of the cSDH (blue box in Fig 2). ${ }^{20,22,27,34,49}$ The direct conversion of an acute SDH into a cSDH is infrequently observed in adult cases only and could not be simulated in animal experiments..$^{20,58,59}$

\section{AGE DIAGNOSTICS General Aspects}

Given the inherent heterogeneity of traumatization and the resulting diversity of SDC appearance and SDC combinations, 


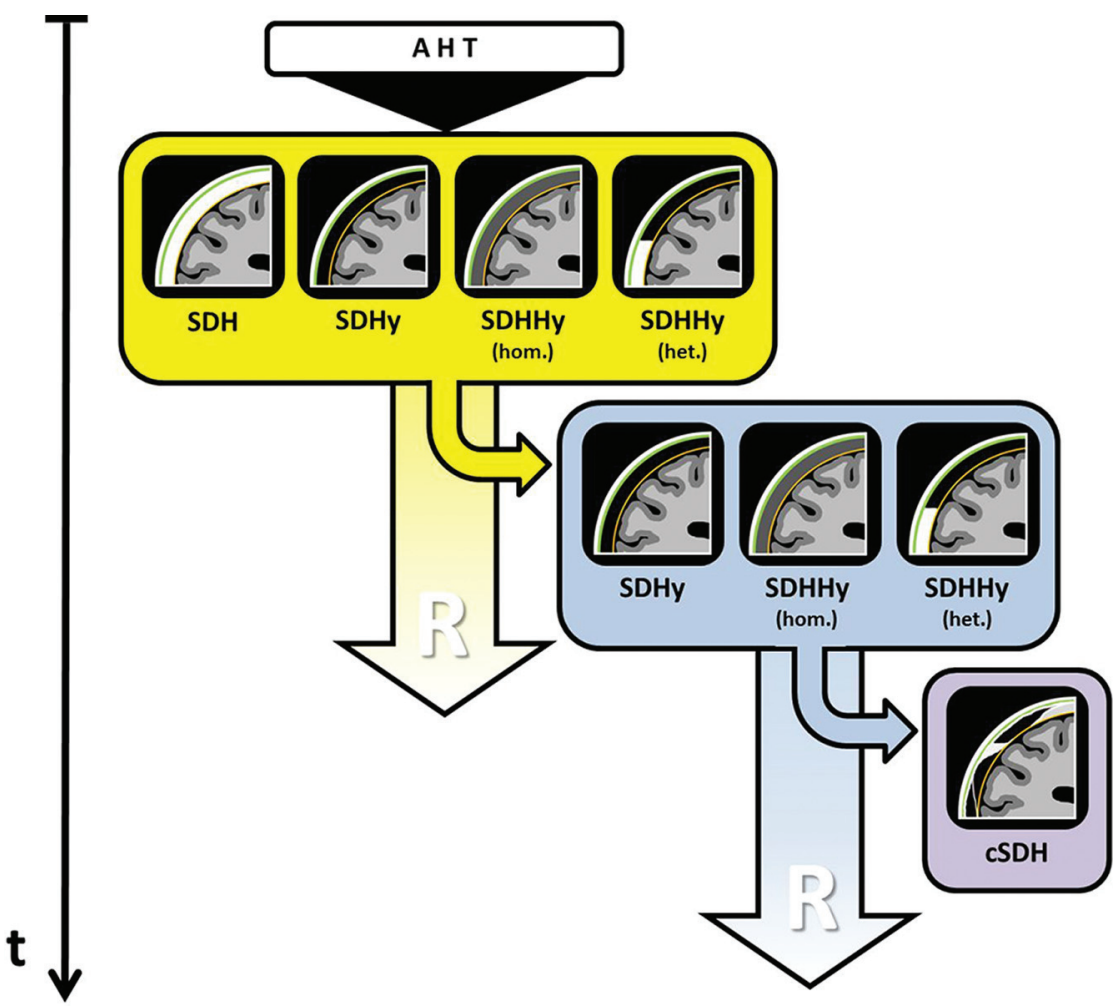

FIG 2. Simplified schematic drawing of the development of cSDHs via SDHys/SDHHys according to Hymel et al, ${ }^{20}$ Hedlund, ${ }^{22}$ Wittschieber et al,,${ }^{27}$ Zouros et al, ${ }^{29}$ Lee et al, ${ }^{34}$ and Lee. ${ }^{49}$ The findings within the yellow box demonstrate the possible SDC entities following AHT that can often be found during initial cross-sectional neuroimaging. A portion of these cases develops further toward the findings shown within the blue box. With time, these SDC entities may then develop into a cSDH (purple box). The pictographs schematically visualize the CT morphologic appearance of the respective SDC. Green indicates the dura mater; orange, the arachnoid membrane; the space in between, the subdural space; hom., homogeneous; het., heterogeneous; $t$, time; $R$, resorption/resolution.

precise dating of SDCs based on neuroimaging alone is unrealistic. However, this issue does not mean that any time-related statements on SDCs are impossible. Hence, it seems appropriate to use more reserved terms such as "age estimation" or "staging." 60

There is general consensus that when interpreting initial imaging studies (mostly CT), SDC features should be described merely (eg, hypodense, isodense, hyperdense, or mixed-density pattern). ${ }^{22,28}$ The possibly rash labeling with temporal assignments such as "acute" or "chronic" should be avoided. $^{22,28}$ In case of the sedimentation of an SDH (or SDHHy), evaluating the sediment instead of the supernatant has been recommended. ${ }^{31}$

Table 1 shows a compilation of the classic SDH stages based on relatively few data found in the literature. ${ }^{22,28,61-66} \mathrm{CT}$ and MR imaging are regarded as complementary methods, which are both indispensable. ${ }^{28,32}$

At present, this insufficient data situation is the most limiting factor preventing more accurate age estimation by neuroimaging. ${ }^{37}$ Resilient reference data on SDH stages can rarely be obtained due to the difficult validation of the time of trauma and the highly variable severity of the injuries. Thus, the combination of insufficient reference data, little specific experience (eg, due to usually low AHT case numbers in nonuniversity institutions), heterogeneous pathophysiologic/anatomic knowledge, and gen- eral lack of consensus concerning methodology (missing guidelines) unsurprisingly results in inconsistent assessments among radiologists as shown recently. ${ }^{67,68}$ These studies reflect the poor data situation and demonstrate the broad and overlapping time intervals of $\mathrm{SDH}$ stages, which represent a general argument against age estimation of SDCs. ${ }^{67,68}$

However, the application of a "minimum age concept" might be an improvement towards an age-diagnostic assessment of the SDC, despite overlapping time intervals of stages. The principle is as follows: If a stage X (eg, "chronic") is found, according to available study data, a minimum time Y (eg, 2 weeks) has elapsed since the trauma has occurred. The fact that the maximum duration of the antecedent stage often overlaps the earliest occurrence of the next stage does not affect the forensic statement (eg, that the SDC is at least 2 weeks old).

The observation of SDC development could be another possibility to increase the accuracy of age estimations of SDCs. To this end, repeated cranial imaging investigations (serial neuroimaging) are required, as long as the clinical state of the patient allows these procedures. ${ }^{22,31,69,70}$

Thus, more reliable age-diagnostic assessments of SDCs necessitate more reference studies and special training programs, imparting specific diagnostic experiences. These would also require a harmonization of methodology and terminology as a precondition. Furthermore, focusing on the density or signal intensity of SDCs alone represents only 1 approach. Other imaging findings might have the potential to support the age estimation of AHT cases in the future - that is, parenchymal shear injuries, bridging vein thromboses/venous injuries, brain edema, subdural neomembranes (see also below: "Hypodense Subdurals: Acute or Chronic?"), the size of the SDC, or other signs of brain damage. ${ }^{22,63,71}$ However, as long as large systematic studies on these topics are missing, being cautious with time-related statements on SDCs is recommended.

\section{Mixed-Density SDCs: Repeated Trauma?}

In initial CT investigations, SDCs frequently show a mixture of hyper- and hypodense proportions (so-called mixed-density pattern) (Fig 1E). This pattern is significantly more frequent in AHT than in accidental head trauma. ${ }^{30,72}$ In the past, the dogma was that such a pattern would represent a combination of "new" and "old" blood, indicating repeated trauma. Today, this view has changed. At least 4 different scenarios have been proposed as explanations for the mixed-density pattern, and 3 of them may be deduced from only 1 single traumatic event (Table 2, upper part). ${ }^{22,28}$ 
Table 3: Possible distinguishing criteria between SDHy and CSDH in neuroimaging ${ }^{\mathrm{a}}$

\begin{tabular}{|c|c|c|c|}
\hline Criterion & SDHy & cSDH & Remarks \\
\hline $\begin{array}{l}\text { Neomembranes/septa/ } \\
\text { chamber formations }\end{array}$ & No & Yes & $\begin{array}{l}\text { MRI more sensitive than CT } \\
\text { IV contrast may improve the detection } \\
\text { of neomembranes } \\
\text { First formation of neomembranes } \\
\text { macroscopically visible after } \sim 10 \text { days }{ }^{74} \\
\text { when using MR imaging contrast after } \\
\sim 2-4 \text { weeks }{ }^{22} \\
\text { Late (chronifying) SDHys may also have } \\
\text { first thin neomembranes (transitional } \\
\text { phase to cSDH, terminologic gray zone) }\end{array}$ \\
\hline Structure/composition & Rather homogeneous (CSF-like) & $\begin{array}{l}\text { Rather heterogeneous/complex } \\
\text { (evidence for blood products } \\
\text { and CSF) }\end{array}$ & $\begin{array}{l}\text { Heterogeneity of different cSDH fluid } \\
\text { areas by neomembrane-associated } \\
\text { chamber formations }\end{array}$ \\
\hline Coexisting brain edema & Possible & Unlikely & Brain edema $=$ rather acute/subacute \\
\hline Growth behavior & $\begin{array}{l}\text { At first, often rapidly progredient } \\
\text { in growth; subsequently, mostly } \\
\text { regredient in growth or static }\end{array}$ & $\begin{array}{l}\text { Rather static/only slowly } \\
\text { progredient in growth }\end{array}$ & Requires serial neuroimaging \\
\hline Density & $\begin{array}{l}\text { Very CSF-like, between } 3.5 \text { and } \\
11.5 \mathrm{HU}^{66}\end{array}$ & $\begin{array}{l}\text { Slightly higher density than CSF } \\
\text { due to admixture of blood } \\
\text { components, between } 6.4 \\
\text { and } 24.6 \mathrm{HU}^{66}\end{array}$ & $\begin{array}{l}\text { Requires standardized measurements } \\
\text { of densities } \\
\text { CSF = 5-10 HU } \\
\text { SDHHys with low blood fraction and } \\
\text { high dilution with CSF are likely to } \\
\text { show HU values just above } 10 \mathrm{HU} \\
\text { as well; thus, differentiation between } \\
\text { SDHy and SDHHy may be difficult }\end{array}$ \\
\hline
\end{tabular}

Scenario 4 ("acute-on-chronic" variant in Table 2) can often be excluded when an acute severe shaking event is suspected because acute rebleeding from cSDH-associated neomembranes is not associated with the typical acute symptomatology of AHT. ${ }^{22,24}$ Then, additional MR imaging and serial neuroimaging may provide more information. ${ }^{68,69}$

In the context of the mixed-density pattern, it has been proposed that SDCs with 2 different densities in " 2 distant locations" may be considered indicators of a so-called "age-different pattern" ${ }^{\prime 60,73}$ - that is, a hypodense frontoparietal SDC in combination with a hyperdense SDC in the posterior fossa, or a hypodense frontoparietal SDC associated with hyperdense clots at the vertex. ${ }^{60}$ Those patterns were reported to be strongly associated with confessions of repeated episodes of violence against the child, suggesting that at least 2 traumatic events occurred. However, there are numerous reports of hypodense SDCs that formed very early after the reported traumatic event (partly even within a few hours), namely without an additional trauma and also on the contralateral side of a hyperdense SDC observed initially. ${ }^{22,27,28,37,69,70}$ One possible explanation for those observations may be arachnoid tears resulting in CSF accumulations within the subdural space corresponding to acute formation of an SDHy or SDHHy.

\section{Hypodense Subdurals: Acute or Chronic?}

The presence of isolated iso- to hypodense SDCs is another typical problem in CT investigations of SDCs (Fig 1B). At least 5 possibilities of interpretation, besides SDHy and SDHHy, compose nearly all time-related SDH stages from hyperacute to chronic (Table 2, lower part). ${ }^{22}$ Hence, a reliable diagnosis and age esti- mation of the SDC are frequently not possible without additional MR imaging and serial neuroimaging, respectively. The diversity of differential diagnoses shown in Table 2 illustrates that the diagnosis of a chronic process (cSDH) may be hasty.

Finally, in many cases, the question is whether the diagnosis is $\mathrm{SDHy}$ or cSDH. While the former is compatible with both a rapid and a delayed process, the latter, in fact, suggests a traumatic event that occurred weeks ago. Several distinguishing criteria have been proposed (Table 3) to address this question. ${ }^{22,27-29,33,66,74}$ The most important criterion is the presence of subdural neomembranes, septa, or chamber-like formations characterizing cSDHs. In neuropathology, the first formation of neomembranes is described as macroscopically visible after $\sim 10$ days. ${ }^{74}$ Their radiologic detection may be challenging and often requires MR imaging, sometimes even supported by intravenous contrast. In those cases, the presence of neomembranes is described after $\sim 2-4$ weeks. $^{22}$

\section{CONCLUSIONS}

SDCs in infants and toddlers represent frequently occurring indicators of AHT. The radiologic analysis and assessment of SDCs remain a challenging task because different SDC entities may appear radiologically very similar at different developmental stages.

As long as no harmonization of terminology, methodology, and age diagnostic criteria of SDCs exists and as long as the scientific data situation has not improved, only rough time-related statements on SDCs will be possible. However, such statements may be helpful if a "minimum age concept" is applied. For exam- 
ple, it is possible to exclude that wide hypodense SDCs with neomembranes formed 2 days ago as suggested by a witness.

In summary, as consensually corroborated by a number of leading medical societies, ${ }^{75}$ the close cooperation and joint evaluation by clinicians, radiologists, and forensic experts remains essential in cases of suspected AHT.

\section{REFERENCES}

1. Peterson C, Xu L, Florence C, et al. The medical cost of abusive head trauma in the United States. Pediatrics 2014;134:91-99 CrossRef Medline

2. Norman RE, Byambaa M, De R, et al. The long-term health consequences of child physical abuse, emotional abuse, and neglect: a systematic review and meta-analysis. PLoS Med 2012;9:e1001349 CrossRef Medline

3. Brown DS, Fang X, Florence CS. Medical costs attributable to child maltreatment a systematic review of short- and long-term effects. Am J Prev Med 2011;41:627-35 CrossRef Medline

4. Di Maio VJ, Di Maio DJ. Neonaticide, infanticide, and child homicide. In: DiMaio VJ, DiMaio D, eds. Forensic Pathology. 2nd ed. Boca Raton: CRC Press; 2001;335-65

5. Keenan HT, Runyan DK, Marshall SW, et al. A population-based study of inflicted traumatic brain injury in young children. JAMA 2003;290:621-26 CrossRef Medline

6. Gill JR, Goldfelder LB, Armbrustmacher V, et al. Fatal head injury in children younger than 2 years in New York City and an overview of the shaken baby syndrome. Arch Pathol Lab Med 2009;133:619-27 Medline

7. Christian CW, Block R; Committee on Child Abuse and Neglect, American Academy of Pediatrics. Abusive head trauma in infants and children. Pediatrics 2009;123:1409-11 CrossRef Medline

8. Matschke J, Herrmann B, Sperhake J, et al. Shaken baby syndrome: a common variant of non-accidental head injury in infants. Dtsch Arztebl Int 2009;106:211-17 Medline

9. Herrmann B. Epidemiologie, Klinik und Konzept des Schütteltrauma-Syndroms. Pädiatrische Praxis 2016;86:297-12. https://cme. mgo-fachverlage.de/uploads/exam/exam_96.pdf. Accessed June 9, 2018

10. Barlow KM, Minns RA. Annual incidence of shaken impact syndrome in young children. Lancet 2000;356:1571-72 CrossRef Medline

11. Jayawant S, Rawlinson A, Gibbon F, et al. Subdural haemorrhages in infants: population-based study. BMJ 1998;317:1558-61 CrossRef Medline

12. Herrmann B. ESPED-Schütteltrauma-Studie. http://www.kindesmiss handlung.de/mediapool/32/328527/data/ESPED_Schuetteltrauma_-_ Zwischenbericht_2009.pdf. Accessed April 14, 2018

13. Fanconi M, Lips U. Shaken baby syndrome in Switzerland: results of a prospective follow-up study, 2002-2007. Eur J Pediatr 2010;169: 1023-28 CrossRef Medline

14. Jenny C, Hymel KP, Ritzen A, et al. Analysis of missed cases of abusive head trauma. JAMA 1999;281:621-26 CrossRef Medline

15. Minns RA, Jones PA, Barlow KM. Outcome and prognosis of nonaccidental head injury in infants. In: Minns RA, Brown JK, eds. Shaking and Other Non-Accidental Head Injuries in Children. London: Mac Keith Press; 2006;364-414

16. Royal College of Paediatrics and Child Health (2013) Child Protection Companion. http://pcouk.org/book.aspx?bookid=1674. Accessed June 9, 2018

17. Royal College of Radiologists and Royal College of Paediatrics and Child Health (9/2017). The radiological investigation of suspected physical abuse in children. https://www.rcr.ac.uk/publication/radio logical-investigation-suspected-physical-abuse-children. Accessed June 9, 2018

18. Tucker J, Choudhary AK, Piatt J. Macrocephaly in infancy: benign enlargement of the subarachnoid spaces and subdural collections. J Neurosurg Pediatr 2016;18:16-20 CrossRef Medline
19. Adamsbaum C. Letter to the editor: subdural collections and abusive head trauma. J Neurosurg Pediatr 2017;19:625 CrossRef Medline

20. Hymel KP, Jenny C, Block RW. Intracranial hemorrhage and rebleeding in suspected victims of abusive head trauma: addressing the forensic controversies. Child Maltreat 2002;7:329-48 CrossRef Medline

21. Vinchon M, de Foort-Dhellemmes S, Desurmont M, et al. Confessed abuse versus witnessed accidents in infants: comparison of clinical, radiological, and ophthalmological data in corroborated cases. Childs Nerv Syst 2010;26:637-45 CrossRef Medline

22. Hedlund G. Abusive head trauma: extra-axial hemorrhage and nonhemic collections. In: Kleinman PK, ed. Diagnostic Imaging of Child Abuse. 3rd ed. Cambridge: Cambridge University Press; 2016;394-452

23. Case ME, Graham MA, Handy TC, et al; National Association of Medical Examiners Ad Hoc Committee on Shaken Baby Syndrome. Position paper on fatal abusive head injuries in infants and young children. Am J Forensic Med Pathol 2001;22:112-22 CrossRef Medline

24. Herrmann B. Misshandlungsbedingte Kopfverletzungen und Schütteltrauma-Syndrom. In: Herrmann B, Dettmeyer R, Banaschak S, et al, eds. Kindesmisshandlung. 3rd ed. Berlin: SpringerVerlag; 2016;39-62

25. Matschke J, Glatzel M. Neuropathologische Begutachtung des nicht akzidentellen Schädel-Hirn-Traumas bei Säuglingen und Kleinkindern. Rechtsmedizin 2008;18:29-35 CrossRef

26. Osborn AG. Trauma. In: Osborn AG, ed. Obsorn's Brain: Imaging, Pathology, and Anatomy. 2nd ed. Salt Lake City: Amirsys; 2013;1-72

27. Wittschieber D, Karger B, Niederstadt T, et al. Subdural hygromas in abusive head trauma: pathogenesis, diagnosis, and forensic implications. AJNR Am J Neuroradiol 2015;36:432-39 CrossRef Medline

28. Vezina $G$. Assessment of the nature and age of subdural collections in nonaccidental head injury with CT and MRI. Pediatr Radiol 2009; 39:586-90 CrossRef Medline

29. Zouros A, Bhargava R, Hoskinson M, et al. Further characterization of traumatic subdural collections of infancy: report of five cases. J Neurosurg 2004;100(5 Suppl Pediatrics):512-18 CrossRef Medline

30. Tung GA, Kumar M, Richardson RC, et al. Comparison of accidental and nonaccidental traumatic head injury in children on noncontrast computed tomography. Pediatrics 2006;118:626-33 CrossRef Medline

31. Vinchon M, Noulé N, Tchofo PJ, et al. Imaging of head injuries in infants: temporal correlates and forensic implications for the diagnosis of child abuse. J Neurosurg 2004;101:44-52 Medline

32. Hedlund G. Subdural hemorrhage in abusive head trauma: imaging challenges and controversies. J Am Osteopath Coll Radiol 2012;1:23-30

33. Case ME. Inflicted traumatic brain injury in infants and young children. Brain Pathol 2008;18:571-82 CrossRef Medline

34. Lee KS, Bae WK, Park YT, et al. The pathogenesis and fate of traumatic subdural hygroma. Br J Neurosurg 1994;8:551-58 CrossRef Medline

35. Squier W, Mack J. The neuropathology of infant subdural haemorrhage. Forensic Sci Int 2009;187:6-13 CrossRef Medline

36. Vinchon M, Noulé N, Soto-Ares G, et al. Subduroperitoneal drainage for subdural hematomas in infants: results in 244 cases. $\mathrm{J} \mathrm{Neu}$ rosurg 2001;95:249-55 CrossRef Medline

37. Vinchon $M$, Noizet $O$, Defoort-Dhellemmes $S$, et al. Infantile subdural hematomas due to traffic accidents. Pediatr Neurosurg 2002; 37:245-53 CrossRef Medline

38. Hwang SK, Kim SL. Infantile head injury, with special reference to the development of chronic subdural hematoma. Childs Nerv Syst 2000;16:590-94 CrossRef Medline

39. Swift DM, McBride L. Chronic subdural hematoma in children. Neurosurg Clin N Am 2000;11:439-46 CrossRef Medline

40. Frasier LD, Coats B. Abusive head trauma: clinical, biomechanical, and imaging considerations. In: Kleinman PK, ed. Diagnostic Imag- 
ing of Child Abuse. 3rd ed. Cambridge: Cambridge University Press; 2015;345-56

41. Cheshire EC, Malcomson RD, Sun P, et al. A systematic autopsy survey of human infant bridging veins. Int J Legal Med 2018;132: 449-61 CrossRef Medline

42. Nierenberger M, Wolfram-Gabel R, Decock-Catrin S, et al. Investigation of the human bridging veins structure using optical microscopy. Surg Radiol Anat 2013;35:331-27 CrossRef Medline

43. Minns RA. Subdural haemorrhages, haematomas, and effusions in infancy. Arch Dis Child 2005;90:883-84 CrossRef Medline

44. Morrison CN, Minns RA. The biomechanics of shaking. In: Minns RA, Brown JK, eds. Shaking and Other Non-Accidental Head Injuries in Children. London: Mac Keith Press; 2006;106-46

45. Yamashima T, Friede RL. Why do bridging veins rupture into the virtual subdural space? J Neurol Neurosurg Psychiatry 1984;47: 121-27 CrossRef Medline

46. v. Düring M, Dermietzel R, Drenckhahn D. Hirnhäute, Ventrikelauskleidung, Liquor cerebrospinalis. In: Benninghoff A, Drenckhahn D, eds. Anatomie. Bd.2, 16th ed. München: Urban\&Fischer/Elsevier; 2004;266-83

47. Mack J, Squier W, Eastman JT. Anatomy and development of the meninges: implications for subdural collections and CSF circulation. Pediatr Radiol 2009;39:200-10 CrossRef Medline

48. Fox RJ, Walji AH, Mielke B, et al. Anatomic details of intradural channels in the parasagittal dura: a possible pathway for flow of cerebrospinal fluid. Neurosurgery 1996;39:84-90; discussion 90-92 CrossRef Medline

49. Lee KS. The pathogenesis and clinical significance of traumatic subdural hygroma. Brain Inj 1998;12:595-603 CrossRef Medline

50. Borzone $\mathrm{M}$, Capuzzo $\mathrm{T}$, Perria $\mathrm{C}$, et al. Traumatic subdural hygromas: a report of $\mathbf{7 0}$ surgically treated cases. J Neurosurg Sci 1983;27:161-65 Medline

51. Kristof RA, Grimm JM, Stoffel-Wagner B. Cerebrospinal fluid leakage into the subdural space: possible influence on the pathogenesis and recurrence frequency of chronic subdural hematoma and subdural hygroma. J Neurosurg 2008;108:275-80 CrossRef Medline

52. Wilberger JE. Pathophysiology of evolution and recurrence of chronic subdural hematoma. Neurosurg Clin N Am 2000;11:435-38 CrossRef Medline

53. Schachenmayr W, Friede RL. The origin of subdural neomembranes. I. Fine structure of the dura-arachnoid interface in man. Am J Pathol 1978;92:53-68 Medline

54. Friede RL, Schachenmayr W. The origin of subdural neomembranes, II: fine structure of neomembranes. Am J Pathol 1978;92: 69-84 Medline

55. Killeffer JA, Killeffer FA, Schochet SS. The outer neomembrane of chronic subdural hematoma. Neurosurg Clin N Am 2000;11:407-12 CrossRef Medline

56. Yamashima T. The inner neomembrane of chronic subdural hematomas: pathology and pathophysiology. Neurosurg Clin N Am 2000;11:413-24 CrossRef Medline

57. Williams VL, Hogg JP. Magnetic resonance imaging of chronic subdural hematoma. Neurosurg Clin N Am 2000;11:491-98 CrossRef Medline

58. Goodell CL, Mealy J Jr. Pathogenesis of chronic subdural hematoma: experimental studies. Arch Neurol 1963;8:429-37 CrossRef Medline

59. Watanabe S, Shimada H, Ishii S. Production of clinical form of chronic subdural hematoma in experimental animals. J Neurosurg 1972;37:552-61 CrossRef Medline

60. Adamsbaum C, Morel B, Ducot B, et al. Dating the abusive head trauma episode and perpetrator statements: key points for imaging. Pediatr Radiol 2014;44(Suppl 4):S578-88 CrossRef Medline

61. Lee KS, Bae WK, Bae HG, et al. The computed tomographic attenuation and the age of subdural hematomas. J Korean Med Sci 1997;12: 353-59 CrossRef Medline

62. Duhem R, Vinchon M, Tonnelle V, et al. Main temporal aspects of the MRI signal of subdural hematomas and practical contribution to dating head injury [in French]. Neurochirurgie 2006;52:93-104 CrossRef Medline

63. Tung GA. Imaging of abusive head trauma. In: Jenny C, ed. Child Abuse and Neglect. Philadelphia: Saunders; 2011;373-91

64. Cramer JA, Rassner UA, Hedlund GL. Limitations of T2*-gradient recalled-echo and susceptibility-weighted imaging in characterizing chronic subdural hemorrhage in infant survivors of abusive head trauma. AJNR Am J Neuroradiol 2016;37:1752-56 CrossRef Medline

65. Bradley WG Jr. MR appearance of hemorrhage in the brain. Radiology 1993;189:15-26 CrossRef Medline

66. Bergström M, Ericson K, Levander B, et al. Computed tomography of cranial subdural and epidural hematomas: variation of attenuation related to time and clinical events such as rebleeding. J Comput Assist Tomogr 1977;1:449-55 CrossRef Medline

67. Sieswerda-Hoogendoorn T, Postema FA, Verbaan D, et al. Age determination of subdural hematomas with CT and MRI: a systematic review. Eur J Radiol 2014;83:1257-68 CrossRef Medline

68. Postema FA, Sieswerda-Hoogendoorn T, Majoie CB, et al. Age determination of subdural hematomas: survey among radiologists. Emerg Radiol 2014;21:349-58 CrossRef Medline

69. Dias MS, Backstrom J, Falk M, et al. Serial radiography in the infant shaken impact syndrome. Pediatr Neuosurg 1998;29:77-85 CrossRef Medline

70. Bradford R, Choudhary AK, Dias MS. Serial neuroimaging in infant with abusive head trauma: timing abusive injuries. J Neurosurg Pediatrics 2013;12:110-19 CrossRef Medline

71. Hahnemann ML, Kinner S, Schweiger B, et al. Imaging of bridging vein thrombosis in infants with abusive head trauma: the "tadpole sign." Eur Radiol 2015;25:299-305 CrossRef Medline

72. Datta S, Stoodley N, Jayawant S, et al. Neuroradiological aspects of subdural haemorrhages. Arch Dis Child 2005;90:947-51 CrossRef Medline

73. Adamsbaum C, Grabar S, Mejean N, et al. Abusive head trauma: judicial admissions highlight violent and repetitive shaking. Pediatrics 2010;126:546-55 CrossRef Medline

74. Walter T, Meissner C, Oehmichen M. Pathomorphological staging of subdural hemorrhages: statistical analysis of posttraumatic histomorphological alterations. Leg Med (Tokyo) 2009;11(Suppl 1): S56-62 CrossRef Medline

75. Choudhary AK, Servaes S, Slovis TL, et al. Consensus statement on abusive head trauma in infants and young children. Pediatr Radiol 2018;48:1048-65 CrossRef Medline 